\title{
IN VIVO COVALENT BINDING OF AFLATOXIN METABOLITES ISOLATED FROM ANIMAL TISSUE TO RAT-LIVER DNA*
}

\author{
W. JaGgi, W. K. Lutz, J. Lüthy, U. ZWeifel and Ch. Schlatter \\ Institut für Toxikologie der Eidgenössischen Technischen Hochschule \\ und der Universität Zürich, $\mathrm{CH}-86(1) 3$ Schwerzenhach. Schweiz
}

(Received ? October 1979)

\begin{abstract}
Ring-labelled $\left[{ }^{14} \mathrm{C}\right]$ aflatoxin $B_{1}\left(A F B_{1}\right)$, prepared by biosynthesis, or generally labelled $\left[{ }^{3} \mathrm{H}\right] A \mathrm{AB}_{1}$ was administered by oral gavage to young adult male rats. After $6 \mathrm{hr}$, the liver was removed and two fractions were isolated, namely macromolecules, which contained about 3 ; in the initial dose of AFB, radioactivity, and water-soluble. low-molecular aflatoxin conjugates containing about $0.2 \%$ of the administered radioactivity. These two fractions were administered orally to other rats in order to determine the potential of radioactive aflatoxin residues for covalent binding to DNA. Such binding can be used as an indicator for carcinogenic potency. Liver DNA was isolated 9-12 hr after administration of the aflatoxin derivatives and in no case was any radioactivity detected on the DNA. It can be deduced on the basis of the limit of detection of radioactivity on the DNA, that macromolecule-bound AFB, derivatives are at least 4000 times less active than AFB, with respect to covalent binding to rat-liver DNA and that the water-soluble conjugates are at least 100 times less potent than AFB, itself. It is concluded that the carcinogenic risk for humans who consume liver or meat containing such aflatoxin residues is negligible when compared with the risk from intake of aflatoxins in other food items.
\end{abstract}

\section{INTRODUCTION}

Aflatoxins are among the strongest hepatocarcinogens. Their mode of carcinogenic action is probably based upon a covalent binding of metabolites to biological macromolecules, and there is increasing evidence that DNA is the most critical target.

Although interaction with DNA appears to be the most important factor in tumour initiation, binding to protein and RNA occurs more frequently. A few hours after administration of a single dose of aflatoxin $\mathrm{B}_{1}\left(\mathrm{AFB}_{1}\right)$ to a rat, less than $10^{\circ} \circ$ of the total macromolecule-bound metabolites is on the DNA, the rest being bound to RNA and to protein (Garner \& Wright, 1975). The preceding paper (Lüthy, Zweifel \& Schlatter, 1980) showed that the total macromoleculebound radioactivity in the liver $24 \mathrm{hr}$ after administration of a single dose of $A F B_{1}$ to a pig represented more than $10 \%$ of the dose. About $1 \%$ of the dose was accounted for by water-soluble, low-molecular-weight aflatoxin metabolites. probably conjugates with glucuronic acid, sulphate or glutathione, and only traces of lipophilic metabolites could be detected.

Since aflatoxins are regular contaminants of groundnut cake used in animal nutrition, aflatoxin residues (including macromolecule-bound aflatoxins and low-molecular conjugates) may be present in foods of animal origin (Purchase. 1972) and may be taken up by humans who consume the livers of these animals. It is possible that aflatoxin metabolites are cleaved from the macromolecules or from the conjugating agent during the process of digestion and are

* Presented in part at the 11th Annual Meeting of the Union of Swiss Societies of Experimental Biology held on 20-21 April 1979 in Geneva. absorbed from the human intestine. No study is available on the carcinogenicity of such aflatoxin derivatives because a long-term carcinogenicity experiment would require considerable effort in the isolation of these derivatives from the livers of aflatoxin-treated animals and their subsequent feeding to other groups of animals.

In this report, the carcinogenicity of macromolecule-bound aflatoxin metabolites and of aflatoxin conjugates is estimated on the basis of a short-term system. DNA binding of carcinogens has been shown to be a useful quantitative measure for the carcinogenic potency of genotoxic compounds (Lutz, 1979), the binding potency being expressed by the so-called 'covalent binding index' (CBI), which shows how many molecules of a chemical are bound covalently per $10^{6}$ DNA nucleotides after the administration of a single dose of $1 \mathrm{mmol} / \mathrm{kg}$ body weight. For rat-liver DNA, it was shown that the CBI is of the order of thousands with strong hepatocarcinogens, hundreds with moderate hepatocarcinogens and tens with weak carcinogens. This quantitative approach is especially suitable for a comparison of structurally related compounds, such as aflatoxins and their macromolecule-bound or conjugated metabolites.

We have therefore administered $A_{F} B_{1}$ labelled with ${ }^{14} \mathrm{C}$ or ${ }^{3} \mathrm{H}$ to rats by gavage, isolated the macromolecules and the water-soluble conjugates of $A F B_{\text {, from }}$ the liver and administered these fractions orally to other rats for a determination of incorporation of radioactivity into the liver DNA of the second group of rats.

\section{EXPERIMENTAL}

Materials and general methods. $\left[{ }^{14} \mathrm{C}\right] \mathrm{AFB}$, was pre- 
pared from sodium $\left[1-{ }^{14} \mathrm{C}\right]$ acetate using Aspergillus parasiticus ATCC 1551, as outlined by Hsieh \& Mateles (1971) and described by Lüthy et al. (1980). $\left[{ }^{3} \mathrm{H}\right] A \mathrm{FB}_{1}$, obtained from Moravek Biochemicals, City of Industry, CA, USA, was specified by the distributor to have a specific activity of $20 \mathrm{Ci} / \mathrm{mmol}$ and a radiochemical purity of $98 \%$ as determined by thinlayer chromatography on silica gel $G$ with chloroform-acetone, 9:1 (v/v). In aqueous media, however, we found that the tritium label was easily exchanged; $24 \mathrm{hr}$ in an aqueous buffer at neutral pH resulted in a $15 \%$ loss of the label, and $37 \%$ was lost within 4 days. Because of this rapid exchange, our $\mathrm{AFB}_{1}$ dose to the rat contained $50 \%$ of the tritium as tritiated water (HTO), so that it was necessary to perform the control experiment described below.

Animals and treatment. Young adult male rats [ZUR:SIV-Z] were used throughout. The aflatoxins were administered in $10 \%$ aqueous ethanol by stomach tube. The aflatoxin metabolites isolated from the livers of the sponsor rats were administered by stomach tube in the solvents indicated below. The animals were killed by open-heart puncture under ether anaesthesia.

Isolation of water-soluble aflatoxin metabolites from rat liver. Liver was homogenized in 3 vols water in a Waring Blender for four periods of $30 \mathrm{sec}$ at high speed. After centrifuging for $1 \mathrm{hr}$ at $12,000 \mathrm{~g}$, the pellet was washed with $6 \mathrm{ml}$ water and centrifuged again, the two supernatants being combined after filtration through paper. In order to separate the low-molecular conjugates from the macromolecule-bound metabolites the supernatant was dialysed three times at $4^{\circ} \mathrm{C}$ against $150 \mathrm{ml}$ water.

The high-molecular content of the dialysis bag was extracted with methylene chloride and centrifuged for $30 \mathrm{~min}$ at $12,000 \mathrm{~g}$ (three times), and the aqueous phase, together with the glutinous layer, was lyophilized. The residue was taken up in $20 \mathrm{ml}$ water and lyophilized again, and this procedure was repeated twice in order to make sure that all exchangeable label was removed. The residue was ground up and suspended in $5 \mathrm{ml} 0.5 \%$ methylcellulose.

The first dialysate was extracted three times with
$50 \mathrm{ml}$ methylene chloride and the aqueous phase was lyophilized as described above. The residue was taken up in $5 \mathrm{ml}$ water and passed through a paper filter.

Isolation of DNA. DNA was isolated from the liver according to Markov \& Ivanov (1974) with the modifications as described (Viviani \& Lutz, 1978). DNA was dissolved in $0.014 \mathrm{M}$-sodium phosphate buffer, pH 6.8 , and counted after the addition of $10 \mathrm{ml}$ InstaGel (Packard Instruments, Downers Grove, IL, USA) in a liquid scintillation counter (Betaszint 5000 , Laboratorium Prof. Dr. Berthold. Wildbad. Federal Republic of Germany). The limit of detection of radioactivity is given by the total variability of the background samples, and one standard deviation (SD) was determined to be $0.7 \mathrm{cpm}$. A limit of detection of $1.5 \mathrm{dpm}(2 \mathrm{SD})$ was therefore adopted for the ${ }^{14} \mathrm{C}$ experiments and $3 \mathrm{dpm}$ for the tritium label.

Experiment on $\left.{ }^{14} \mathrm{C}\right] A F B_{1}$. Two $280-\mathrm{g}$ male rats were each given orally a dose of $3.6 \times 10^{7} \mathrm{dpm}$ $(320 \mu \mathrm{g})\left[{ }^{14} \mathrm{C}\right] \mathrm{AFB}_{1} / \mathrm{kg}$. After $6 \mathrm{hr}$, the high-molecular fraction was isolated from the combined livers as described above and administered in three portions of about $5.5 \mathrm{ml}$ at hourly intervals to another rat, which was killed $10 \mathrm{hr}$ after receiving the last portion, for isolation of its liver DNA. Numerical details are presented in Table 1.

Experiment on $\left[{ }^{3} H\right] A F B_{1}$. A $288-8$ male rat received by oral gavage $9 \times 10^{8} \mathrm{dpm}(12 \mu \mathrm{g})\left[{ }^{3} \mathrm{H}\right] \mathrm{AFB}_{1} / \mathrm{kg}$, together with $1.2 \times 10^{9} \mathrm{dpm}$ tritiated water contaminant $/ \mathrm{kg}$. After $6 \mathrm{hr}$, the aflatoxin metabolites were isolated from the liver as described above, and the high-molecular derivatives were administered to one rat and the low-molecular metabolites to another rat. Liver DNA was isolated from these rats after $9 \mathrm{hr}$. Numerical details are given in Table 2.

Control experiment with tritiated water, HTO. One $290-g$ rat received by oral gavage $4.2 \times 10^{9} \mathrm{dpm}$ HTO $/ \mathrm{kg}$. After $6 \mathrm{hr}$, the macromolecules were isolated from the liver as described above and administered to another $(330-\mathrm{g})$ rat $\left(5.3 \times 10^{4} \mathrm{dpm} / \mathrm{kg}\right)$, from which $16.7 \mathrm{mg}$ liver DNA was isolated after $9 \mathrm{hr}$. The gross radioactivity $(22.7 \mathrm{cpm}, 5.40 \mathrm{~min}$ counting time) was not significantly different from that of the control DNA (22.5 cpm).

Table 1. Binding of macromolecule-bound $\left[{ }^{14} \mathrm{C}\right]$ afiatoxin $B_{1}$ to rat-liver DNA $10 \mathrm{hr}$ after its oral administration

\begin{tabular}{lll}
\hline \multicolumn{1}{c}{ Parameter } & $\begin{array}{c}\text { Control } \\
\text { rat }\end{array}$ & \multicolumn{1}{c}{$\begin{array}{c}\text { Treated } \\
\text { rat }\end{array}$} \\
\hline $\begin{array}{l}\text { Body weight (g) } \\
\text { Radioactivity administered (dpm/kg) }\end{array}$ & 221 & 228 \\
Liver DNA & 0 & $3.6 \times 10^{6}$ \\
Amount in scintillation vial (mg) & 1.69 & 1.62 \\
Gross activity (cpm; 240-min count) & 23.6 & 22.9 \\
Specific activity of DNA (dpm/mg)* & - & $<0.9$ \\
DNA binding (dpm/mg DNA) per dose (dpm/kg) & - & $<2.6 \times 10^{-7}$ \\
Covalent binding index (CBI)t & - & $<80 \ddagger$ \\
\hline
\end{tabular}

-Based on $1.5 \mathrm{dpm}$ as limit of detection.

$+\mathrm{CBI}=(\mu \mathrm{mol}$ chemical bound per mol DNA phosphate $) /(\mathrm{mmol}$ chemical administered per $\mathrm{kg}$ body weight).

$\ddagger C B I$ determined for aflatoxin $B_{1}$ under similar experimental conditions was 10,000 . 
Table 2. Binding of macromolecule-bound $\left[{ }^{3} H\right]$ aflatoxin $B_{1}$ and water-soluble $\left[{ }^{3} H\right]$ aflatoxin conjugates to rat-liver DNA $9 \mathrm{hr}$ after their oral administration

\begin{tabular}{lccc}
\hline \multicolumn{1}{c}{ Parameter } & \multicolumn{2}{c}{ Rat treated with } \\
\cline { 3 - 4 } & $\begin{array}{c}\text { Control } \\
\text { rat }\end{array}$ & $\begin{array}{c}\text { Macromol.-bound } \\
\text { aflatoxin }\end{array}$ & $\begin{array}{c}\text { Water-soluble } \\
\text { conjugates }\end{array}$ \\
\hline Body weight (g) & 310 & 320 & 415 \\
Radioactivity administered (dpm/kg) & 0 & $2.8 \times 10^{7}$ & $8.3 \times 10^{5}$ \\
Liver DNA & 11.9 & 14.6 & 11.4 \\
Amount in scintillation vial (mg) & 22.5 & 22.8 & 22.4 \\
$\begin{array}{l}\text { Gross activity (cpm; 200-min count) } \\
\text { Specific activity of DNA (dpm/mg)* }\end{array}$ & - & $<0.21$ & $<0.26$ \\
DNA binding (dpm/mg DNA) per dose (dpm/kg) & - & $<7.4 \times 10^{-9}$ & $<3.2 \times 10^{-7}$ \\
Covalent binding index (CBI) $\dagger$ & - & $<2.3 \ddagger$ & $<98 \ddagger$
\end{tabular}

- Based on $3 \mathrm{dpm}$ as limit of detection.

$+\mathrm{CBI}=(\mu \mathrm{mol}$ chemical bound per mol DNA phosphate $) /(\mathrm{mmol}$ chemical administered per $\mathrm{kg}$ body weight).

$\ddagger$ CBI determined for aflatoxin $B_{1}$ under similar experimental conditions was 10,000 .

\section{RESULTS}

The fraction of aflatoxin radioactivity recovered from the rat liver $6 \mathrm{hr}$ after a single dose of $\mathrm{AFB}_{1}$ was found to be $9 \%$ in the experiment with the ${ }^{14} \mathrm{C}$-label and $7 \%$ with the ${ }^{3} \mathrm{H}$-label. Of this total radioactivity, $40 \%\left({ }^{14} \mathrm{C}\right.$-label) and $46 \%$ ( ${ }^{3} \mathrm{H}$-label) was bound to macromolecules, $2 \%\left({ }^{3} \mathrm{H}\right.$-label) was recovered in the low-molecular fraction. The fraction of macromolecule-bound aflatoxin metabolites is of the same order as that found in the pig (Lüthy et al. 1980), and is in good agreement with earlier studies in the rat (Wogan, Edwards \& Shank, 1967).

Tables 1 and 2 give data on the binding experiments and show that in no case was any radioactivity detectable on the liver DNA of the rats given the radiolabelled aflatoxin derivatives isolated from the livers of the sponsor rats. The lowest corresponding value for the $C B I$ is easily calculated from these data if the limit of detection of radioactivity $(1.5 \mathrm{dpm}$ for ${ }^{14} \mathrm{C}, 3 \mathrm{dpm}$ for tritium) is divided by the amount of DNA isolated and by the dose of radioactivity administered to the animal.

\section{Macromolecule-bound aflatoxin derivatives}

With the ${ }^{14} \mathrm{C}$-label (Table 1), the limit of detection of binding of macromolecule-bound aflatoxin metabolites to rat liver DNA was found to be 80 in the CBI units ( $\mu \mathrm{mol}$ chemical bound/mol nucleotides)/(mmol chemical administered/kg body weight). With the ${ }^{3} \mathrm{H}$-label (Table 2), a larger amount of radioactivity was available so that a value of 2.3 resulted for the highest possible CBI for rat liver DNA. This figure is more than 4000 times below the $\mathrm{CBI}$ of $\mathrm{AFB}_{1}$ itself.

\section{Low-molecular aflatoxin conjugates}

Only one experiment, with the tritium label (Table 2), was performed with this minor fraction isolated from the liver of a rat that had received $A F B_{1}$. The radioactivity that could have been expected from an experiment with ${ }^{14} \mathrm{C}$ would have been too low for a DNA binding experiment with a second rat. The limit of detection of a CBI of less than 100 shows that this fraction of the aflatoxin residues in rat liver is more than 100 times less active than $A F B_{1}$ itself with respect to DNA binding in the rat liver.

\section{HTO control}

Because of the contamination of the $\left[{ }^{3} \mathrm{H}\right] \mathrm{AFB}_{1}$ with tritiated water a check was made on the extent to which HTO was incorporated into the macromolecular fraction used in the main experiment. The amount of tritium administered was about twice as much as that given in the $\left[{ }^{3} \mathrm{H}\right] \mathrm{AFB}_{1}$ experiment, but only about $0.001 \%$ of the radioactivity administered was recovered on the macromolecules. Administration of this total macromolecular fraction to a second rat resulted in no detectable radioactivity on the liver DNA. These results show that the high percentage of HTO in the original ${ }^{3} \mathrm{H}-\mathrm{AFB}_{1}$ dose did not affect the interpretation of the results.

There is a possibility that macromolecule-bound aflatoxin metabolites lose their label during the isolation procedure and during the time between the administration of the radioactivity and its measurement on the DNA. A lack of any radioactivity on the DNA could then be due partly to a loss of the label. This possibility can be excluded, however, since it was shown by the repeated lyophilization steps, carried out at daily intervals, that less than. $1 \%$ of the radioactivity on the macromolecule-bound aflatoxin metabolites was exchanged within 1 day:

\section{DISCUSSION}

CBIs for aflatoxins have so far been determined with $\mathrm{AFB}_{1}$ by Campbell, Hayes \& Newberne (1978) Croy, Essigmann, Reinhold \& Wogan (1978), Garner \& Wright (1975), Preston, Hayes \& Campbell (1976) and Swenson, Lin, Miller \& Miller (1977) and also in this laboratory (Lutz, 1979), figures between 10,000 and 30,000 having been reported for rat-liver DNA: $\mathrm{AFB}_{2}$ has been investigated by Swenson et al. (1977). $\mathrm{AFM}_{1}$ by Lutz (1979) and AFG, by Garner, Martin, Smith, Coles \& Tolson (1979). The CBI of these three afatoxins ranged between 500 and 4000 so that a good quantitative correlation with the observed carcinogenicity from long-term experiments was established. Some early experiments with $A F B_{1}$ and $A F G_{1}$, based upon tritiated afiatoxins, were performed by Lijinsky, Lee \& Gallagher (1970), who obtained a CBI for $\mathrm{AFB}_{1}$ much lower than those found in all the 
other laboratories, possibly as a result of using an unstable tritium label.

Our results with aflatoxin residues isolated from rat liver reveal that neither macromolecule-bound metabolites nor low-molecular conjugates exhibit any DNA-binding ability. Macromolecule-bound $\mathrm{AFB}_{1}$ residues could be at the worst $\mathbf{4 0 0 0}$ times less hepatocarcinogenic than $\mathrm{AFB}_{1}$ itself, while the conjugates are at least 100 times less active than $A F B_{1}$ with respect to covalent binding to rat-liver DNA.

A CBI describes the DNA damage to be expected after the administration of a unit dose. If the real amount of DNA-bound chemical from a specific dose has to be assessed. the actual dose has also to be taken into account. As a first approximation, a multiplication of the CBI with the dose might be performed, although this is only a valid procedure if a linear dose-binding relationship has been demonstrated over the complete dose range in question.

The actual exposure of humans to aflatoxin residues from pork liver can be estimated on the basis of the metabolism data presented by Lüthy et al. (1980), following the making of appropriate assumptions on the contamination of the pig diet with aflatoxins. It can then be deduced that pork liver in Switzerland contains less than $0.1 \mathrm{ppm}$ macromolecule-bound aflatoxin metabolites, while the amount of watersoluble aflatoxin conjugates will be much lower even than that. In muscle, the main edible tissue, levels of both types of residue are again lower by several orders of magnitude.

If such low exposure is taken into account in assessing the carcinogenic risk of a population consuming pork liver or meat, the risk must be considered negligible when compared with that from the direct intake of aflatoxins from nuts, milk and other sources.

\section{REFERENCES}

Campbell, T. C., Hayes, J. R. \& Newberne, P. M. (1978). Dietary lipotropes, hepatic microsomal mixed-function oxidase activities, and in vivo covalent binding of aflatoxin $B_{1}$ in rats. Cancer Res. 38, 4569.

Croy, R. G., Essigmann, J. M.. Reinhold. V. N. \& Wogan, G. N. (1978). Identification of the principal aflatoxin $B_{1}$-DNA adduct formed in vivo in rat liver. Proc. natn. Acad. Sci. U.S.A. 75, 1745.

Garner, R. C., Martin, C. N., Smith. J. R. L.. Coles, B. F. \& Tolson, M. R. (1979). Comparison of aflatoxin $B_{1}$ and aflatoxin $G$, binding to cellular macromolecules in vitro, in vivo and after peracid oxidation; characterization of the major nucleic acid adducts. Chemico-Biol. Interactions 26, 57.

Garner, R. C. \& Wright, C. M. (1975). Binding of $\left[{ }^{14} \mathrm{C}\right] \mathrm{af}-$ latoxin $B_{1}$ to cellular macromolecules in the rat and hamster. Chemico-Biol. Interactions 11, 123.

Hsieh, D. P. H. \& Mateles, R. I. (1971). Preparation of labelled aflatoxins with high specific activities. Appl. Microbiol. 22, 79.

Lijinsky, W., Lee, K. Y. \& Gallagher, C. H. (1970). Interaction of aflatoxins $B_{1}$ and $G_{1}$ with tissues of the rat. Cancer Res. 30, 2280.

Lüthy, J., Zweifel, U. \& Schlatter, Ch. (1980). Metabolism and tissue distribution of $\left[{ }^{14} \mathrm{C}\right]$ aflatoxin $\mathrm{B}_{1}$ in pigs. $F d$ Cosmet. Toxicol. 18, 253.

Lutz, W. K. (1979). In vivo covalent binding of organic chemicals to DNA as a quantitative indicator in the process of chemical carcinogenesis. Mutation Res. 65, 289.

Markov, G. G. \& Ivanov, I. G. (1974). Hydroxyapatite column chromatography in procedures for isolation of purified DNA. Analyt. Biochem. 59, 555.

Preston, R. S., Hayes, J. R. \& Campbell, T. C. (1976). The effect of protein deficiency on the in vivo binding of aflatoxin $B_{1}$ to rat liver macromolecules. Life Sci. 19 , 1191.

Purchase, I. F. H. (1972). Aflatoxin residues in food of animal origin. Fd Cosmet. Toxicol. 10, 531.

Swenson, D. H., Lin, J.-K. Miller, E. C. \& Miller, J. A (1977). Aflatoxin $B_{1}-2,3$-oxide as a probable intermediate in the covalent binding of aflatoxins $B_{1}$ and $B_{2}$ to rat liver DNA and ribosomal RNA in vivo. Cancer Res. 37. 172.

Viviani, A. \& Lutz, W. K. (1978). Modulation of the binding of the carcinogen benzo(a)pyrene to rat liver DNA in vivo by selective induction of microsomal and nuclear aryl hydrocarbon hydroxylase activity. Cancer Res. 38. 4640.

Wogan, G. N., Edwards, G. S. \& Shank, R. C. (1967). Excretion and tissue distribution of radioactivity from aflatoxin $\mathrm{B}_{1}-{ }^{14} \mathrm{C}$ in rats. Cancer Res. 27, 1729. 